Check for updates

Cite this: RSC Adv., 2021, 11, 21116

\title{
Structure modulation on fluorescent probes for biothiols and the reversible imaging of glutathione in living cells $\uparrow$
}

\author{
Yu Li,,$_{+}^{a}$ Li Chen, ț,$^{b}$ Yan Zhu, ${ }^{\text {a }}$ Liming Chen, ${ }^{a}$ Xianglin Yu, ${ }^{b}$ Junbo Li ${ }^{c}$ \\ and Dugang Chen $(\mathbb{D} * \mathrm{~b}$
}

\begin{abstract}
The detection of small molecular biothiols (cysteine, homocysteine and glutathione) is of great importance, as they involve in a series of physiological and pathological processes and are associated with many diseases. To realize the real-time monitoring of a specific biothiol, a rapid and reversible probe is required. Therefore, three probes, namely, o-MNPy, $m-M N P y$ and $p-M N P y$, with pyridine substituted $\alpha$, $\beta$-unsaturated ketone as the recognition site, were reported here, and the reactivity of the recognition site was finely tuned by the connection mode of the pyridine unit. To single out the optimal one, the response performances of three probes toward each biothiol were systemically studied, taking the differences of the intracellular contents of three biothiols into account during the evaluation. Biothiols reacted with the probes through Michael addition, and results showed that the slight structural variations could affect the performances of the probes obviously. $p$-MNPy with the pyridine unit connected to the recognition site through the para-position of the nitrogen atom, revealed the best sensing ability among the three probes. It demonstrated rapid response, good selectivity and sensitivity, excellent pH adaptability to Cys and GSH, and displayed reversible detection toward GSH. Finally, $p$-MNPy was successfully applied to track the GSH fluctuations under the oxidative stress stimulated by $\mathrm{H}_{2} \mathrm{O}_{2}$ in living cells.
\end{abstract}

rsc.li/rsc-advances

\section{Introduction}

Nonprotein biothiols, including cysteine (Cys), homocysteine (Hcy) and glutathione (GSH), are the most important smallmolecular sulfur containing amino acids in living cells, which play vital roles in a series of physiological and pathological activities. ${ }^{1-3}$ The abnormal fluctuations of the endogenous biothiol levels are usually valuable signals for malfunction of cells and organs, and therefore are closely related to some symptoms and diseases. The deficiency of Cys is associated with symptoms such as slow growth, hair pigmentation, lethargy, etc.4-8 The excess of Hcy in serum is an independent risk factor for cardiovascular disease..$^{9,10}$ GSH is the most abundant biothiol, which acts as an antioxidant to defend against attack from free

${ }^{a}$ Hubei Provincial Academy of Eco-Environmental Sciences, Wuhan 430072, China. E-mail: zhuyan2007v@163.com

${ }^{b}$ Key Laboratory for Green Chemical Process of Ministry of Education, School of Chemical Engineering and Pharmacy, Wuhan Institute of Technology, Wuhan 430205, China. E-mail: dg.chen@wit.edu.cn

'School of Chemistry and Environmental Engineering, Wuhan Institute of Technology, Wuhan 430205, China

$\dagger$ Electronic supplementary information (ESI) available: The ESI includes the experimental procedures, structural characterization data, and some other auxiliary pictures. See DOI: 10.1039/d1ra03221f

\$ These authors contributed equally. radicals and sustains the intracellular redox homeostasis, ${ }^{\mathbf{1 1 , 1 2}}$ and an imbalance in its expression is implicated with cancer, HIV, Parkinson, etc.13,14 Therefore, it is significant to discriminate the biothiols and monitor the level changes in living cells, which may offer meaningful information for the diagnosis and treatment of related diseases.

Fluorescent probes have attracted considerable attentions in the determination of the variety and content of bio-species, ascribed to their advantages of high sensitivity, facile operation, visualization and noninvasiveness. ${ }^{15-22} \mathrm{~A}$ variety of fluorophores have been utilized to construct fluorescent probes for biothiol detection, which covered a wide range of emission signals from green to near-infrared fluorescence that could satisfy the requirements in different situations..$^{23-29}$ And some probes could discriminate Cys, Hcy and GSH selectively. ${ }^{30-34}$ However, most of the reported probes are not reversible, which means the probes could respond to biothiols only once and cannot track the changes of biothiols dynamically in living cells. This defect may be not favorable for providing pathophysiological insights. In order to solve this problem, reversible probes that can implement the real-time quantitative detection of biothiols are valuable. ${ }^{35-38}$ From the perspective of molecular design, the reaction between the probe and biothiols should be reversible. Among the extensively studied reaction mechanisms for biothiol detection, such as nucleophilic substitution, ${ }^{39-41}$ 
(a)
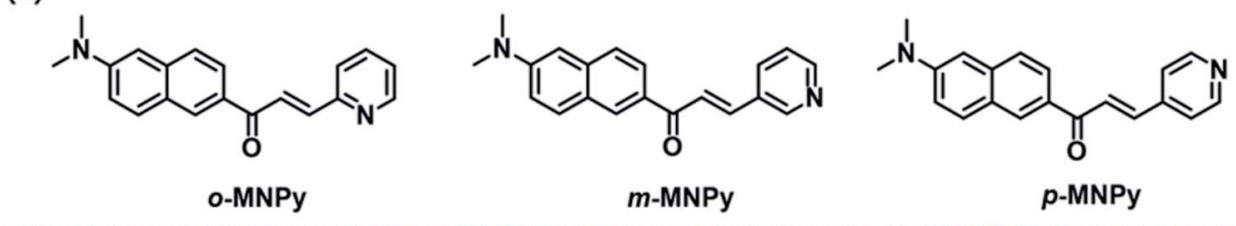

(b)
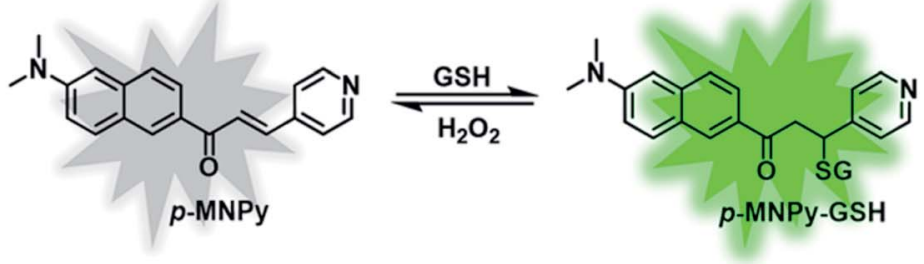

Scheme 1 The molecular structures of (a) o-MNPy, $m$-MNPy and $p$-MNPy in this work, and (b) the schematic illustration of the reversible recognition of GSH by $p$-MNPy.

nucleophilic addition and cyclization, ${ }^{42-44}$ Michael addition, ${ }^{36-38}$ and multisite reaction strategy ${ }^{45-47}$ Michael addition is more reasonable to build a reversible probe credited to its nature of reversibility. Wang and coworkers reported the first fluorescent probe ThiolQuant Green (TQ Green) for quantitative detection of GSH in living cells through carefully adjusting the properties of the Michael acceptor. ${ }^{48,49}$ Urano and coworkers obtained a mitochondrion targeted rapid fluorescent probe QuicGSH (QG3.0) for GSH quantification through rational molecular design, which was based on fluorescence resonance energy transfer (FRET) mechanism with rhodamine as the platform. ${ }^{36}$ These two probes are representative examples for ratiometric and reversible detection of GSH. We have reported a lysosometargeted two-photon fluorescent probe MNPO for rapid and selective detection of cysteine in living cells. ${ }^{50}$ We mainly focused on the targeting ability and high sensitivity of this twophoton activable probe, whereas the structure of the recognition site "pyridine substituted $\alpha, \beta$-unsaturated ketone" was not carefully studied. The capability of this probe to reversibly sense biothiols was not taken seriously either at that time. However, the Michael addition mechanism of this probe makes the reversible detection possible. Considering that the fluorogen "amino naphthalene ketone" has demonstrated high brightness during the imaging and the modulation of the Michael acceptor is crucial for optimizing the performance of the probe,$^{48}$ we adopted the same fluorogen skeleton as MNPO and tried to regulate the property of the Michael acceptor by altering the connection mode of the pyridine unit, in order to pick out the optimal probe for reversible detection of biothiols.

Here, three probes, $\boldsymbol{o}$-MNPy, $\boldsymbol{m}$-MNPy and $\boldsymbol{p}$-MNPy, were reported (Scheme 1). In these molecules, dimethylaminonapthalone moiety acted as the signal reporting unit, and pyridine modified $\alpha, \beta$-unsaturated ketone moiety which was a Michael acceptor acted as the recognition site for biothiols. As the pyridine unit could be attached to the molecular skeleton through three positions, namely, the ortho, meta, and para position of the nitrogen atom, three probe molecules mentioned above were designed and synthesized accordingly. The different connection modes of pyridine would affect the reactivity of the Michael acceptor, and hence lead to different response performances of the probes, including signal to noise ratio, response speed, and even selectivity. The structureproperty relationships of three probes were systemically investigated, and $\boldsymbol{p}$-MNPy showed better performances than the other two. Then the reversibility of $\boldsymbol{p}$-MNPy was carefully studied, as well as the sensitivity and selectivity during the detection of GSH. Finally, $\boldsymbol{p}$-MNPy was utilized to image the GSH fluctuations under the oxidative stress in living cells.

\section{Experimental}

\subsection{Materials, instruments and measurements}

The starting materials and dry $N, N$-dimethylformamide (DMF) were commercially obtained from Energy Chemical Corporation. Phosphate buffered saline (PBS) was purchased from Maokangbio Corporation. Other organic solvents were purchased from Sinopharm Chemical Reagent Co., Ltd HeLa cells were obtained from iCell Bioscience Inc. The detailed information of instruments, sample preparation and test condition, cytotoxicity assay, cell culture and cell imaging process are all listed in the ESI. $\dagger$ The experiments in solution were performed at room temperature, and after the addition of $\mathrm{Cys} / \mathrm{Hcy} / \mathrm{GSH}$, the probe solution was let stand for $10 \mathrm{~min}$ before any spectra measurements.

\subsection{Synthesis}

1-(6-(Dimethylamino)naphthalen-2-yl)ethenone (MN): 1-(6aminonaphthalen-2-yl)ethenone ( $150 \mathrm{mg}, 0.8 \mathrm{mmol})$ and $\mathrm{K}_{2} \mathrm{CO}_{3}$ $(552 \mathrm{mg}, 4 \mathrm{mmol}$ ) were mixed in $15 \mathrm{~mL}$ of DMF at room temperature, and then iodomethane $(0.249 \mathrm{~mL}, 4 \mathrm{mmol})$ was added. $10 \mathrm{~min}$ later, the mixture was heated to $60^{\circ} \mathrm{C}$ and stirred for $12 \mathrm{~h}$. After cooling to room temperature, the mixture was poured to ethyl acetate and washed with water for three times, then the organics were dried over anhydrous $\mathrm{Na}_{2} \mathrm{SO}_{4}$. After the solvent was removed under reduced pressure, the residue was purified by a silica-gel column chromatography using petroleum ether/ethyl acetate $(\mathrm{v} / \mathrm{v}, 8 / 1)$ as eluent to give the product 
MN as a brown solid (124 mg, 72.84\%). ${ }^{1} \mathrm{H}$ NMR $(400 \mathrm{MHz}$, DMSO- $\left.d_{6}\right) \delta[\mathrm{ppm}]: 8.44(\mathrm{~s}, 1 \mathrm{H}), 7.92(\mathrm{~d}, J=8 \mathrm{~Hz}, 1 \mathrm{H}), 7.81(\mathrm{dd}, J$ $=8 \mathrm{~Hz}, 1 \mathrm{H}), 7.68(\mathrm{~d}, J=8 \mathrm{~Hz}, 1 \mathrm{H}), 7.29(\mathrm{dd}, J=8 \mathrm{~Hz}, 1 \mathrm{H}), 6.96$ (d, $J=4 \mathrm{~Hz}, 1 \mathrm{H}), 3.07$ (s, 6H), $2.62(\mathrm{~s}, 3 \mathrm{H})$.

(E)-1-(6-(Dimethylamino)naphthalen-2-yl)-3-(pyridine-2-yl) prop-2-en-1-one (o-MNPy): MN (250 mg, $1.17 \mathrm{mmol}$ ) and picolinaldehyde ( $375.71 \mathrm{mg}, 3.50 \mathrm{mmol}$ ) were dissolved in a mixture of ethanol ( $5 \mathrm{~mL})$ and THF $(5 \mathrm{~mL})$ under an argon atmosphere, and piperidine $(0.3 \mathrm{~mL})$ and acetic acid $(0.6 \mathrm{~mL})$ were slowly added to the solution separately. Then the mixture was heated to $80{ }^{\circ} \mathrm{C}$ and stirred for $96 \mathrm{~h}$. After cooling to room temperature, the mixture was poured to ethyl acetate, and washed with $\mathrm{Na}_{2} \mathrm{CO}_{3}$ aqueous solution (10\%). The organic layer was dried over anhydrous $\mathrm{Na}_{2} \mathrm{SO}_{4}$. After the solvent was removed under reduced pressure, the residue was purified by silica-gel column chromatography using petroleum ether/ethyl acetate (v/v, 8/1) to give product $\boldsymbol{o}$-MNPy as a solid (152 mg, 43\%). ${ }^{1} \mathrm{H}$ NMR (400 MHz, DMSO- $\left.d_{6}\right) \delta[\mathrm{ppm}]: 8.72-8.69(\mathrm{~m}, 2 \mathrm{H}), 8.34(\mathrm{~d}, J=16 \mathrm{~Hz}$, $1 \mathrm{H}), 8.02(\mathrm{~d}, J=8 \mathrm{~Hz} 1 \mathrm{H}), 7.98-7.92(\mathrm{~m}, 3 \mathrm{H}), 7.76-7.72(\mathrm{~m}, 2 \mathrm{H})$, 7.47-7.44 (m, 1H), 7.31 (dd, $J=12 \mathrm{~Hz}, 1 \mathrm{H}), 6.99(\mathrm{~s}, 1 \mathrm{H}), 3.09$ (s, $6 \mathrm{H}) .{ }^{13} \mathrm{C}$ NMR $\left(100 \mathrm{MHz}, \mathrm{DMSO}-d_{6}\right) \delta[\mathrm{ppm}]: 188.38,153.56$, $150.85,150.43,142.27,137.88,137.61,131.38,137.27,130.89$, 126.78, 125.76, 125.22, 125.05, 125.02, 124.85, 116.89, 105.24, 40.62. HRMS for $\mathrm{C}_{20} \mathrm{H}_{18} \mathrm{~N}_{2} \mathrm{O}[\mathrm{M}+\mathrm{H}]^{+}$, calculated: 303.1497; found: 303.1490. Mass error: $-2.31 \mathrm{ppm}$.

(E)-1-(6-(Dimethylamino)naphthalen-2-yl)-3-(pyridine-3-yl) prop-2-en-1-one (m-MNPy): similar procedures to $\boldsymbol{o}$-MNPy except that the starting materials were $\mathbf{M N}$ (122 $\mathrm{mg}, 0.572$ $\mathrm{mmol}$ ) and nicolinaldehyde (183.68 mg, $1.71 \mathrm{mmol}) . \mathbf{m}$-MNPy was obtained as an orange solid (35 mg, 20\%). ${ }^{1} \mathrm{H}$ NMR (400 MHz, DMSO- $\left.d_{6}\right) \delta[\mathrm{ppm}]: 9.06(\mathrm{~s}, 1 \mathrm{H}), 8.79(\mathrm{~s}, 1 \mathrm{H}), 8.62(\mathrm{~d}, J=$ $4 \mathrm{~Hz}, 1 \mathrm{H}), 8.39$ (d, $J=8 \mathrm{~Hz}, 1 \mathrm{H}), 8.25$ (d, $J=16 \mathrm{~Hz}, 1 \mathrm{H}), 8.00-$ $7.94(\mathrm{~m}, 2 \mathrm{H}), 7.79-7.73$ (m, 2H), 7.52 (dd, $J=8 \mathrm{~Hz}, 1 \mathrm{H}), 7.33$ (dd, $J=8 \mathrm{~Hz}, 1 \mathrm{H}), 6.99$ (d, $J=4 \mathrm{~Hz}, 1 \mathrm{H}), 3.09$ (s, 6H). ${ }^{13} \mathrm{C}$ NMR $(100$ MHz, DMSO- $\left.d_{6}\right) \delta[\mathrm{ppm}]: 187.98,151.19,150.82,150.62,139.61$, 137.86, 135.46, 131.45, 131.27, 131.21, 130.87, 126.67, 125.03, 124.97, 124.59, 124.33, 116.90, 105.29, 40.61. HRMS for $\mathrm{C}_{20} \mathrm{H}_{18} \mathrm{~N}_{2} \mathrm{O}[\mathrm{M}+\mathrm{H}]^{+}$, calculated: 303.1497; found: 303.1498 . Mass error: $0.33 \mathrm{ppm}$.
(E)-1-(6-(Dimethylamino)naphthalen-2-yl)-3-(pyridine-4-yl) prop-2-en-1-one ( $\boldsymbol{p}$-MNPy): similar procedures to $\boldsymbol{o}$-MNPy except that the starting materials were $\mathbf{M N}(273 \mathrm{mg}, 1.281 \mathrm{mmol})$ and isonicolinaldehyde (379.33 mg, $3.54 \mathrm{mmol}$ ). $\boldsymbol{p}$-MNPy was obtained as an orange solid (97 mg, 25.04\%). ${ }^{1} \mathrm{H}$ NMR $(400 \mathrm{MHz}$, DMSO- $\left.d_{6}\right) \delta[\mathrm{ppm}]: 8.79(\mathrm{~s}, 1 \mathrm{H}), 8.69(\mathrm{~d}, J=8 \mathrm{~Hz}, 2 \mathrm{H}), 8.32(\mathrm{~d}, J=$ $16 \mathrm{~Hz}, 1 \mathrm{H}), 8.00(\mathrm{dd}, J=8 \mathrm{~Hz}, 1 \mathrm{H}), 7.96(\mathrm{~d}, J=8 \mathrm{~Hz}, 1 \mathrm{H}), 7.87$ (d, $J=8 \mathrm{~Hz}, 2 \mathrm{H}), 7.75-7.67$ (m, 2H), 7.33 (dd, $J=8 \mathrm{~Hz}, 1 \mathrm{H}), 6.99$ (d, $J$ $=4 \mathrm{~Hz}, 1 \mathrm{H}), 3.09(\mathrm{~s}, 6 \mathrm{H}) .{ }^{13} \mathrm{C}$ NMR $\left(100 \mathrm{MHz}, \mathrm{DMSO}-d_{6}\right) \delta[\mathrm{ppm}]:$ 188.06, 150.93, 150.81, 142.61, 140.21, 137.99, 131.75, 131.31, 130.69, 127.05, 126.77, 125.00, 124.96, 122.94, 116.96, 105.31, 40.62. HRMS for $\mathrm{C}_{20} \mathrm{H}_{18} \mathrm{~N}_{2} \mathrm{O}[\mathrm{M}+\mathrm{H}]^{+}$, calculated: 303.1497; found: 303.1499. Mass error: $0.66 \mathrm{ppm}$.

\section{Results and discussion}

\subsection{Design and synthesis}

The rigid and planar structure of the donor- $\pi$-acceptor $(\mathrm{D}-\pi-\mathrm{A})$ type MN (Scheme 2) had shown high brightness during the cell imaging, ${ }^{50}$ therefore, it was selected as the signal reporting unit of the probe. Pyridine substituted $\alpha, \beta$-unsaturated ketone, making up of the Michael acceptor, acted as the recognition site. The different connection modes of the pyridine group in $\boldsymbol{o}$ MNPy, $\boldsymbol{m}$-MNPy and $\boldsymbol{p}$-MNPy would affect the electronic properties of the Michael acceptor in different degrees and hence alter the reactivities of the probes with biothiols. So, the whole three probe molecules were designed and synthesized to single out the best one for biothiol detection. The synthetic routes of the intermediates and the target molecules are shown in Scheme 2. MN was prepared according to the literature with some modifications in a high yield using $\mathrm{K}_{2} \mathrm{CO}_{3}$ as the catalyst for the nucleophilic substitution. ${ }^{51}$ The probe molecules were synthesized by aldol condensation between $\mathbf{M N}$ and the corresponding pyridine aldehyde, where weak base and acid were chosen as the co-catalyst. The reactions lasted for 4 days, while full conversion of the reactants was not observed. The yields were only around $20 \%$ to $40 \%$. The probe molecules were fully characterized by ${ }^{1} \mathrm{H}$ NMR, ${ }^{13} \mathrm{C}$ NMR and HRMS (Fig. S1-S5†).

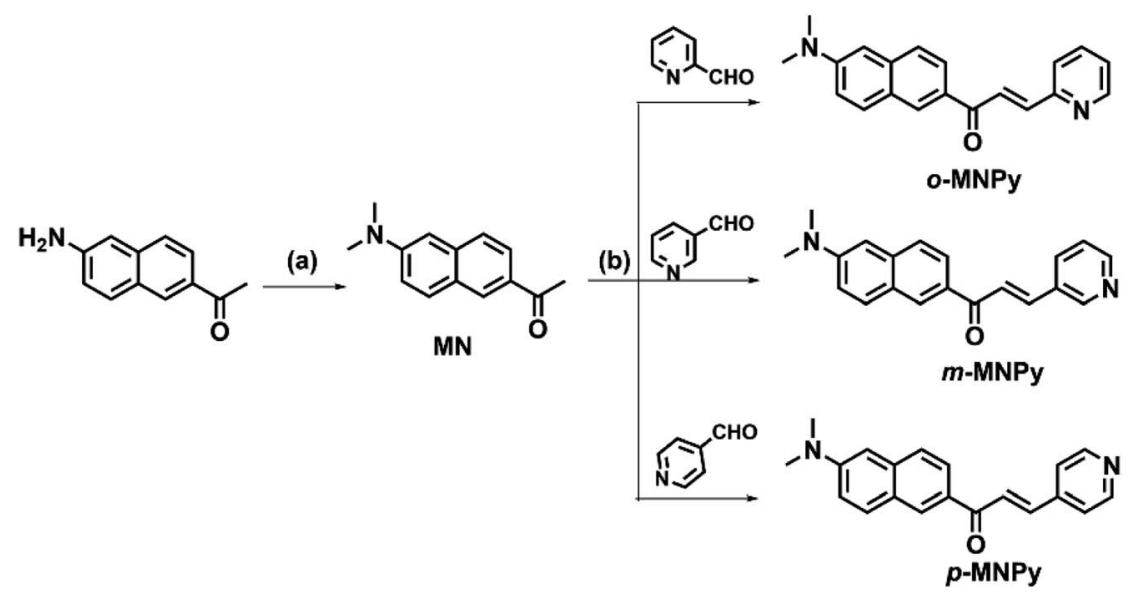

Scheme 2 The synthetic routes of o-MNPy, $m$-MNPy and $p$-MNPy. Conditions: (a) $\mathrm{CH}_{3} l, \mathrm{~K}_{2} \mathrm{CO}_{3}, \mathrm{DMF}, 60^{\circ} \mathrm{C}$; (b) piperidine, acetic acid, ethanol/ $\mathrm{THF}, 80^{\circ} \mathrm{C}, 96 \mathrm{~h}$ 
(a)

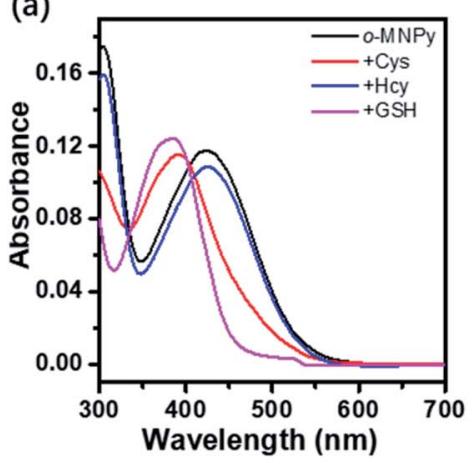

(d)

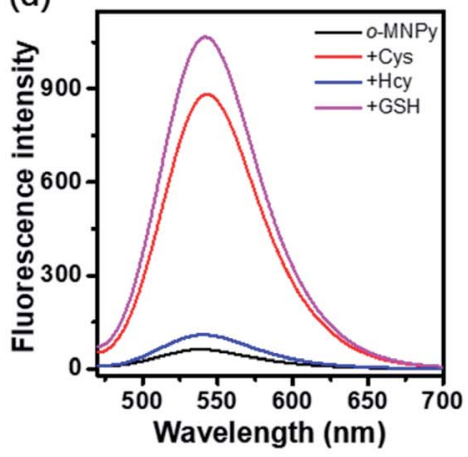

(b)

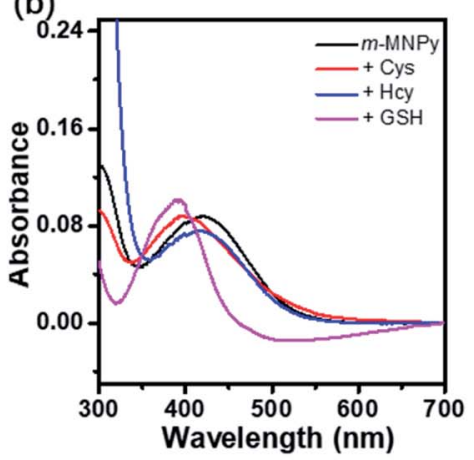

(e)

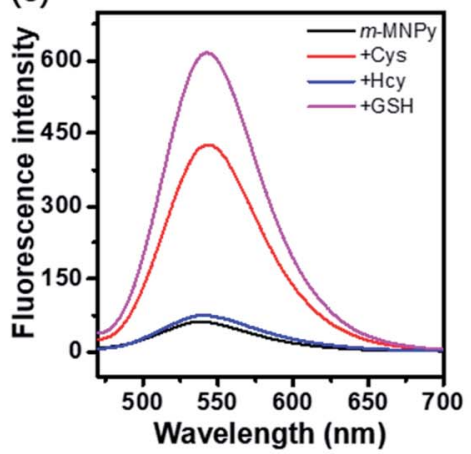

(c)

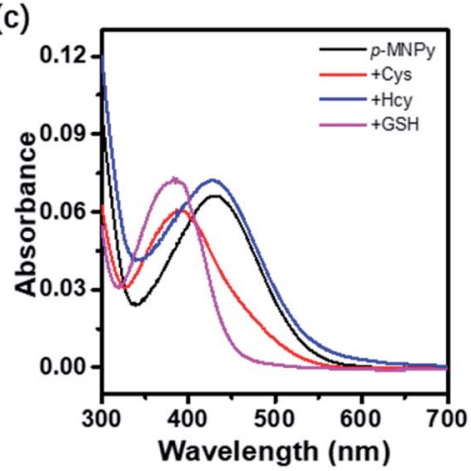

(f)

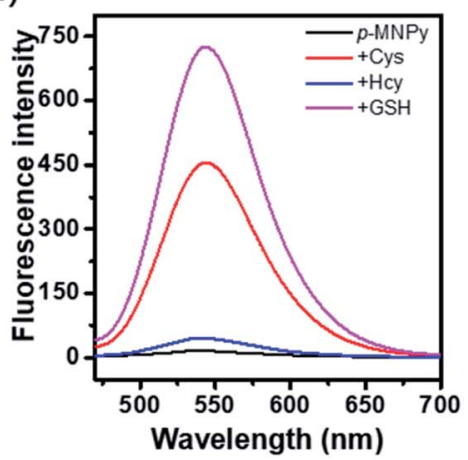

Fig. 1 The UV-vis spectra of (a) o-MNPy, (b) $m$-MNPy and (c) $p$-MNPy, and the fluorescence spectra of (d) o-MNPy, (e) $m$-MNPy and (f) $p$-MNPy before and after the addition of Cys $(100 \mu \mathrm{M})$, Hcy $(10 \mu \mathrm{M})$ and $\mathrm{GSH}(5 \mathrm{mM})$. The concentration of each probe was $10 \mu \mathrm{M}$ in PBS $($ containing $10 \%$ DMSO).

\subsection{Photophysical properties}

The photophysical properties of the three probes were studied in PBS. In most literatures, the concentrations of the three biothiols were set in the same level (for example $100 \mu \mathrm{M}$ ) to examine the performances of the probes. However, considering their huge differences in intracellular contents (Cys 30-200 $\mu \mathrm{M}$, Hcy 5-13 $\mu \mathrm{M}$, and GSH $0.5-10 \mathrm{mM}$ ), ${ }^{52}$ the concentration of Cys, Hcy and GSH during this test was selected as $100 \mu \mathrm{M}, 10 \mu \mathrm{M}$ and $5 \mathrm{mM}$, respectively. As shown in Fig. 1, the absorption maxima of $\boldsymbol{o}$-MNPy and $\boldsymbol{p}$-MNPy were at 429 and $430 \mathrm{~nm}$, respectively, while that of $\boldsymbol{m}$-MNPy was blue shifted to $419 \mathrm{~nm}$. As is known, the conjugation degree of the compound and the strength of the intramolecular charge transfer (ICT) process could both impact the absorption spectrum of a molecule. ${ }^{24,53}$ Since the structures of the three probes were similar, we supposed that the $10 \mathrm{~nm}$ blue-shift of the absorption maximum of $\boldsymbol{m}$-MNPy was ascribed to the weaker ICT process compared with the other two. This result also indicated the inferior electron-withdrawing ability of the meta-connected pyridine. When GSH was added to the probes severally, the absorption spectra of the three probes were all blue shifted to around $390 \mathrm{~nm}$, which suggested the happening of the Michael addition reaction between the probes and GSH resulting in the interruption of the conjugation (a)

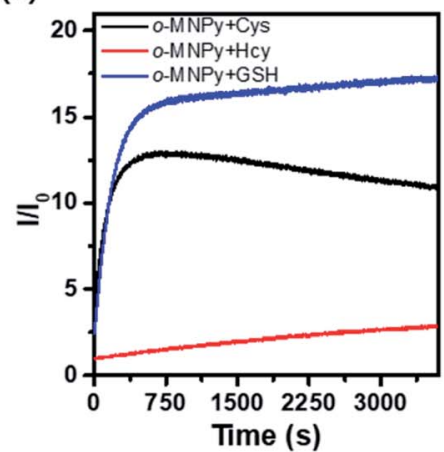

(b)

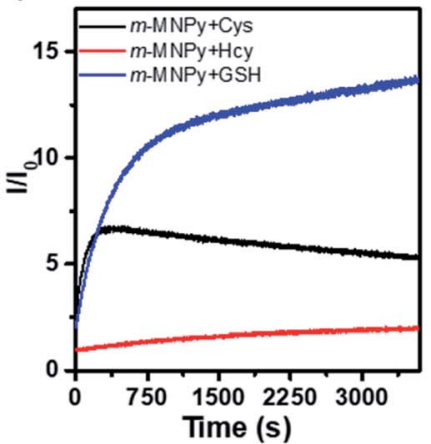

(c)

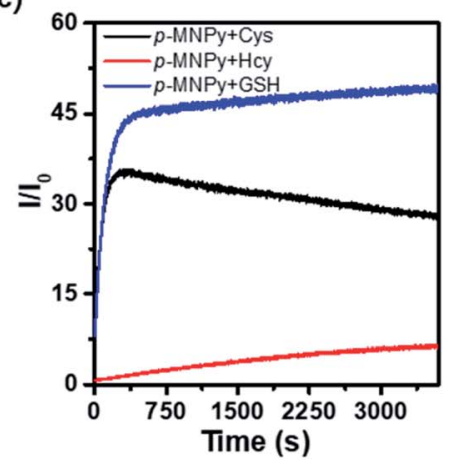

Fig. 2 The time-dependent fluorescence intensity changes of (a) o-MNPy, (b) $m$-MNPy and (c) $p$-MNPy in the presence of three biothiols. Concentrations: probe $10 \mu \mathrm{M}$, Cys $100 \mu \mathrm{M}$, Hcy $10 \mu \mathrm{M}$, and GSH 5 mM. 
between $\mathbf{M N}$ and the pyridine unit. The same reaction also occurred upon Cys treatment, as the absorption peaks of the probes were blue-shifted as well. We suspected that these similar changes of the absorption spectra in the presence of Cys and GSH were probably due to the structural similarity of the two biothiols that GSH contains Cys in its structure. However, in the presence of $10 \mu \mathrm{M}$ of Hcy, the spectra changed little. Unlike the other two probes, $\boldsymbol{p}$-MNPy could respond to higher concentration of Hcy $(100 \mu \mathrm{M})$ (Fig. S6 $\dagger)$. The fluorescence of the probes was obviously turned on in the presence of Cys and GSH with the emission maxima at around $543 \mathrm{~nm}$. The enhancements of the fluorescence intensity during the addition of GSH were 17,11 , and 43 -fold for $\boldsymbol{o}$-, $\boldsymbol{m}$-, and $\boldsymbol{p}$-MNPy, respectively. And similar to the results from the absorption spectra, the addition of Hcy showed little influence on the fluorescence. The quantum yields (QYs) of $\boldsymbol{o}$-, $\boldsymbol{m}$-, and $\boldsymbol{p}$-MNPy in PBS (containing 10\% DMSO) were calculated to be $0.16 \%$, $0.19 \%$ and $0.13 \%$, respectively, using quinine sulfate as the standard ( $\mathrm{QY}=0.53$ in $\left.0.1 \mathrm{M} \mathrm{H}_{2} \mathrm{SO}_{4}\right)$, and they were significantly increased to $5.64 \%, 3.56 \%$ and $6.55 \%$, respectively, in the presence of GSH. All the spectral data were summarized in Table S1. $\dagger$ As both the absorption and emission experiments had shown that the three molecules could respond to Cys and GSH in the range of their intracellular concentrations, they had great potentials as the fluorescent probe for biothiols in living cells.

\subsection{Response speed}

As an important factor, the response speed of the probe toward each biothiol was further investigated, which was associated with the efficiency of the detection. The time-dependent fluorescence changes of the probes toward Cys, Hcy and GSH were shown in Fig. 2. Agreed with the findings in the previous part, all the three probes showed much more distinct response toward Cys and GSH than Hcy. For o- and $\boldsymbol{p}$-MNPy, their reactivities with Cys and GSH were very similar. In $10 \mathrm{~min}$, the fluorescence intensity of $\boldsymbol{o}$-MNPy could reach a plateau after the addition of Cys or GSH, and an even shorter time of 8 min was needed for $\boldsymbol{p}$-MNPy to complete the reactions. However, $\boldsymbol{m}$ MNPy spent more than $20 \mathrm{~min}$ to reach its largest fluorescence intensity in the presence of GSH. We speculated that the different reactivities of three probes were probably due to the subtle structural changes of the Michael acceptors, where $m$ connected pyridine unit showed the worst electron-withdrawing ability and could not activate the adjacent double bond as efficiently as the $o$ - or $p$-connection mode. It was interesting that the fluorescence intensities of three probes in the presence of Cys tended to decrease with the increase of time. Just like the probes designed for Cys with acryloyl group as the recognition site, ${ }^{23,34,54,55}$ we supposed that further reaction between the " $-\mathrm{NH}_{2}$ " of Cys and the " $\mathrm{C}=\mathrm{O}$ " of the probe took place with a stable 7-membered ring generated after the Michael addition, which weakened the ICT process of the D-A system and made the emission decrease over time. This phenomenon might be used to differentiate Cys and GSH. Compared with the other two probes, $\boldsymbol{p}$-MNPy had demonstrated both larger fluorescence on/ off ratio and faster response speed, therefore, it was chosen as the fluorescent probe for Cys and GSH with its other performances studied in the following parts.

\subsection{Sensitivity of $p$-MNPy}

The fluorescence changes of $\boldsymbol{p}$-MNPy with the addition of different amount of Cys or GSH were recorded as shown in Fig. 3 and S7. $\dagger$ There was a linear relationship between the concentration of Cys and the fluorescence intensity of the probe when Cys was added to the probe in the range of 1-10 $\mu \mathrm{M}$, and for $\mathrm{GSH}$, the concentration range was $0.2-1 \mathrm{mM}$. Based on the equation of $3 \sigma / k$, the limit of detection (LOD) of $\boldsymbol{p}$-MNPy was calculated to be $0.029 \mu \mathrm{M}$ for Cys and $1.40 \mu \mathrm{M}$ for GSH, where $\sigma$ is the standard deviation of the blank solution $(\sigma=0.0998)$ and $k$ is the slope of the linear fitting curve $(k=10.473$ for Cys, and 213.35 for GSH). The LOD was much lower than the corresponding intracellular biothiol contents, which demonstrated that $\boldsymbol{p}$-MNPy was sensitive enough to detect the Cys or GSH in living cells.

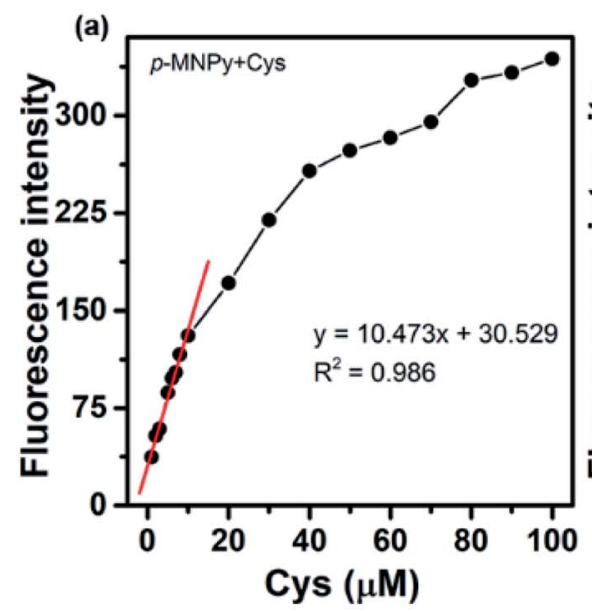

(b)

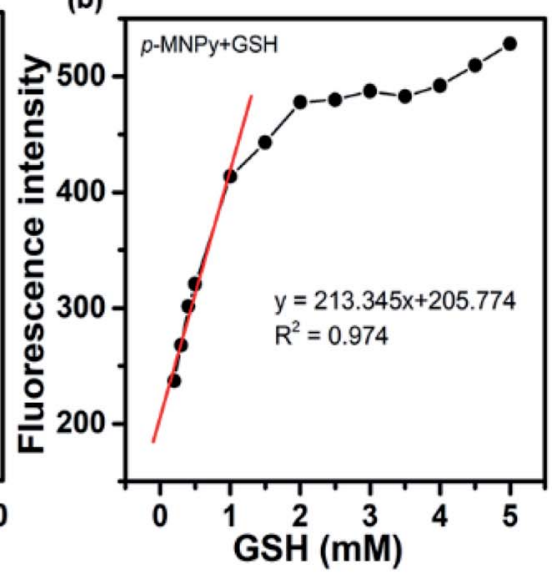

Fig. 3 The changes of fluorescence intensity of $p$-MNPy as the addition of different amount of (a) Cys, and (b) GSH. Concentrations: $p$-MNPy 10 $\mu \mathrm{M}$, Cys 1-100 $\mu \mathrm{M}$, GSH 0.1-5 mM. 

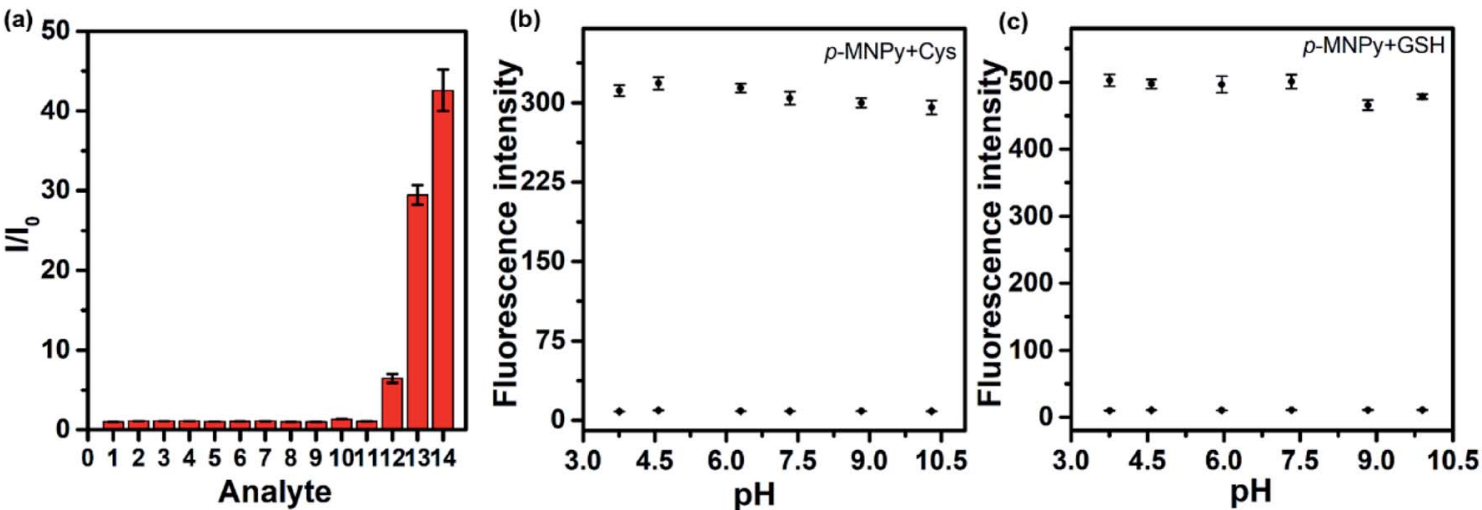

Fig. 4 (a) The fluorescence responses of p-MNPy $(10 \mu \mathrm{M})$ toward various bio-species. 1 control, 2 histidine, 3 glycine, 4 lysine, 5 proline, 6 glutamic acid, 7 glucose, $8 \mathrm{Na}_{2} \mathrm{~S}, 9 \mathrm{Na}_{2} \mathrm{SO}_{3}, 10 \mathrm{H}_{2} \mathrm{O}_{2}, 11 \mathrm{NaClO}, 12 \mathrm{Hcy}, 13 \mathrm{Cys}, 14 \mathrm{GSH}$. I0 refers to the fluorescence intensity of the pure probe solution. The concentration of each analyte was $100 \mu \mathrm{M}$, except that Hcy was $10 \mu \mathrm{M}$ and GSH was $5 \mathrm{mM}$. The pH-dependent fluorescence changes of $p$-MNPy toward (b) Cys and (c) GSH in PBS (containing 10\% DMSO).

\subsection{Selectivity and $\mathrm{pH}$ adaptability}

Previous study had revealed that $\boldsymbol{p}$-MNPy did not respond to 10 $\mu \mathrm{M}$ of Hcy. To further confirm whether Hcy would interfere with the recognition process of Cys/GSH by the probe, the related absorption and fluorescence spectra of $\boldsymbol{p}$-MNPy with Cys/GSH in the absence and presence of Hcy were recorded (Fig. S8†). As expected, $\boldsymbol{p}$-MNPy displayed satisfactory selectivity toward Cys/ GSH among the biothiols. Then the responses of $\boldsymbol{p}$-MNPy to other common bio-species were also investigated, such as some representative amino acids (histidine, glycine, lysine, proline, glutamic acid), glucose, strong nucleophile $\left(\mathrm{Na}_{2} \mathrm{~S}\right.$ and $\left.\mathrm{Na}_{2} \mathrm{SO}_{3}\right)$, and reactive oxygen species $\left(\mathrm{H}_{2} \mathrm{O}_{2}\right.$ and $\left.\mathrm{NaClO}\right)$. As shown in Fig. 4a, S9 and S10, $\dagger$ only Cys and GSH could induce strong (a)
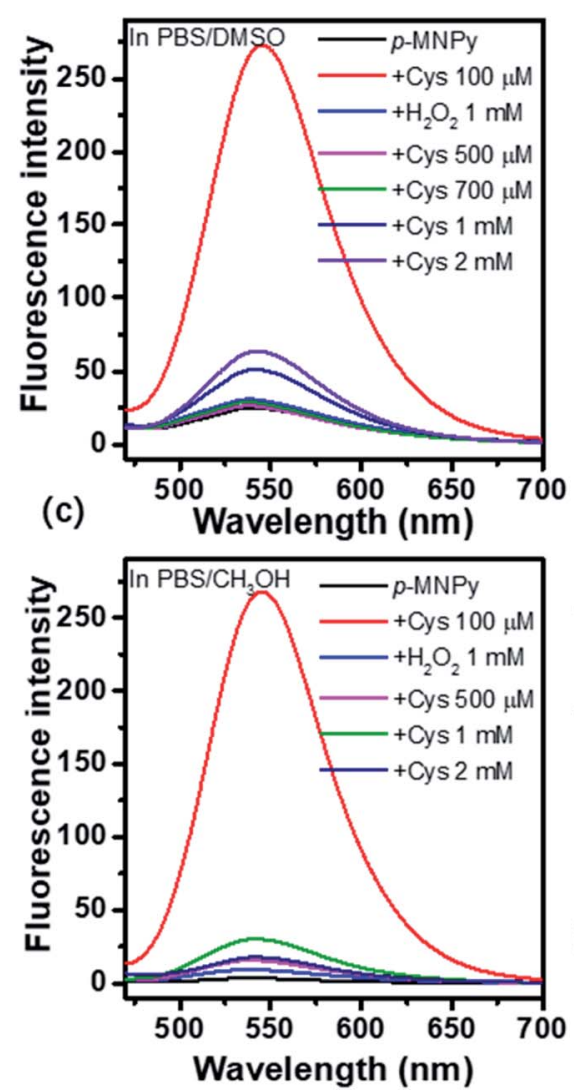

(b)
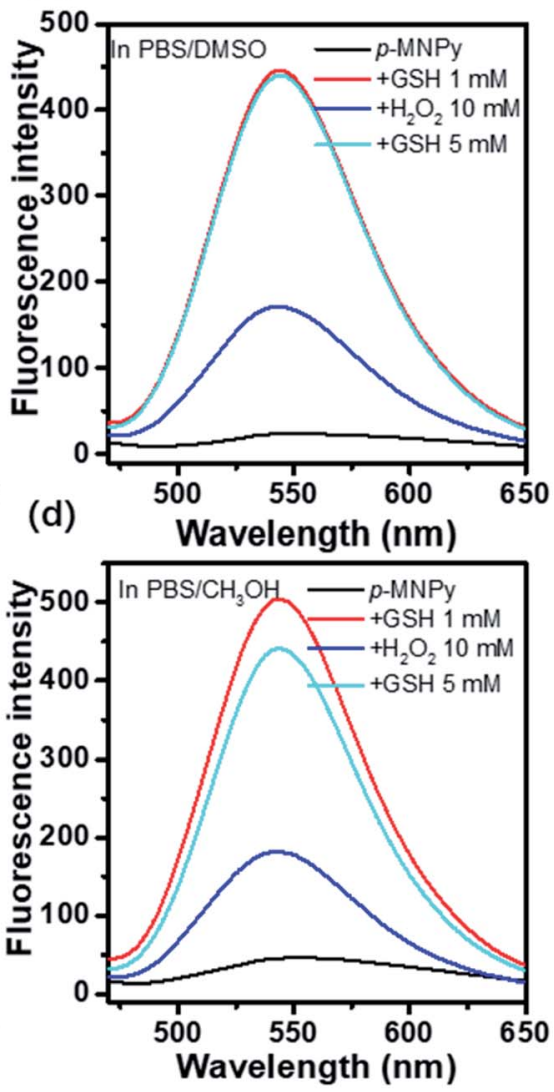

Fig. 5 The fluorescence changes of $p$-MNPy with the addition of (a) Cys or (b) GSH and $\mathrm{H}_{2} \mathrm{O}_{2}$ in PBS/DMSO (v/v, 9/1), and with the addition of (c) Cys or (d) $\mathrm{GSH}$ and $\mathrm{H}_{2} \mathrm{O}_{2}$ in $\mathrm{PBS} / \mathrm{CH}_{3} \mathrm{OH}(\mathrm{v} / \mathrm{v}, 8 / 2)$. 
fluorescence when each analyte was added to the probe separately, and the fluorescence of the probe with Cys or GSH did not change apparently in the presence of each analyte, which indicated that the probe $\boldsymbol{p}$-MNPy was free from the interferences of the above bio-species. The sensing ability of $\boldsymbol{p}$-MNPy toward Cys and GSH was further investigated in different $\mathrm{pH}$ environment (Fig. 4b, c and S11 $\dagger$ ). The reaction between biothiol and $\boldsymbol{p}$ MNPy was supposed to be Michael addition, namely, the nucleophilic sulfhydryl group of Cys or GSH would attack the carbon-carbon double bond in the Michael acceptor of $\boldsymbol{p}$-MNPy. Normally, the nucleophilicity of sulfhydryl group would reduce as the decrease of the $\mathrm{pH}$ of the solution. However, the sensing capacity of $\boldsymbol{p}$-MNPy toward both Cys and GSH seemed to be independent with the environmental $\mathrm{pH}$ in the range of $\mathrm{pH} 3.5-$ 10.5. We speculated that the reactivity of the Michael acceptor would be increased in acidic condition owing to the protonation of the pyridine unit, which may offset the inhibition of the reactivity of the sulfhydryl group in low $\mathrm{pH}$ environment. In summary, the probe $\boldsymbol{p}$-MNPy was appropriate for the application in cells with excellent $\mathrm{pH}$ tolerance.

\subsection{Reversible recognition toward GSH}

As the Michael addition has inherent reversibility, the reversible detection ability of $\boldsymbol{p}$-MNPy toward Cys and GSH was studied. $\mathrm{H}_{2} \mathrm{O}_{2}$, an intracellular reactive oxygen species, was utilized to induce the oxidative stress, which can oxidize GSH to its oxidative form (GSSG) and therefore decrease the content of GSH. As shown in Fig. 5a, Cys turned on the fluorescence of the probe in PBS/DMSO (v/v, 9/1), and excessive $\mathrm{H}_{2} \mathrm{O}_{2}$ could efficiently quench the fluorescence as expected. However, the continuous addition of Cys again could not relight up the probe, even though much excessive amount of Cys was applied. In the contrast, the addition of GSH could turn on the fluorescence of the probe again after quenched by $\mathrm{H}_{2} \mathrm{O}_{2}$ (Fig. 5b). To exclude the effect of solvents, the reversibility of the probe was further studied in another solvent system, $\mathrm{PBS} / \mathrm{CH}_{3} \mathrm{OH}(\mathrm{v} / \mathrm{v}, 8 / 2)$. As shown in Fig. 5c and d, similar results were found as those in PBS/DMSO that $\boldsymbol{p}$-MNPy still showed reversible recognition ability to GSH, but not to Cys. We supposed that these different response behaviors of the probe may be due to the higher reactivity of Cys to $\mathrm{H}_{2} \mathrm{O}_{2}$, which might be confirmed by the fact that 10 eq. of $\mathrm{H}_{2} \mathrm{O}_{2}$ have quenched the fluorescence induced by Cys more efficiently than that induced by GSH. In addition, dilution experiments and HRMS were also employed to validate the reversible mechanism of the probe. As shown in Fig. S12, $\dagger$ further addition of GSH to the 10-fold diluted solution of $\boldsymbol{p}$ $\mathbf{M N P y}+$ GSH made the absorbance at $390 \mathrm{~nm}$ and the fluorescence intensity at $542 \mathrm{~nm}$ obviously increased, and in Fig. S13 and $\mathrm{S} 14 \uparrow$ the fragment peaks of the adduct $\boldsymbol{p}$-MNPy-GSH and the recovered $\boldsymbol{p}$-MNPy by $\mathrm{H}_{2} \mathrm{O}_{2}$ could both be found in the HRMS. All these results manifested that $\boldsymbol{p}$-MNPy could respond to GSH reversibly. At last, it may need to be noted that the effect of $\mathrm{GSH}$ and $\mathrm{H}_{2} \mathrm{O}_{2}$ on the probe was not proportionable, as $10 \mathrm{mM}$ of $\mathrm{H}_{2} \mathrm{O}_{2}$ was necessary to offset the impact of $1 \mathrm{mM}$ of GSH on $\boldsymbol{p}$-MNPy, and only $5 \mathrm{mM}$ of additional GSH could recover the fluorescence.

\subsection{Fluorescence imaging in living cell}

As the previous experiments displayed that $\boldsymbol{p}$-MNPy showed the potential to monitor GSH reversibly, its sensing performance in living cells was further investigated. Before the live cell imaging, the biocompatibility of $\boldsymbol{p}$-MNPy was first studied by MTT assay.

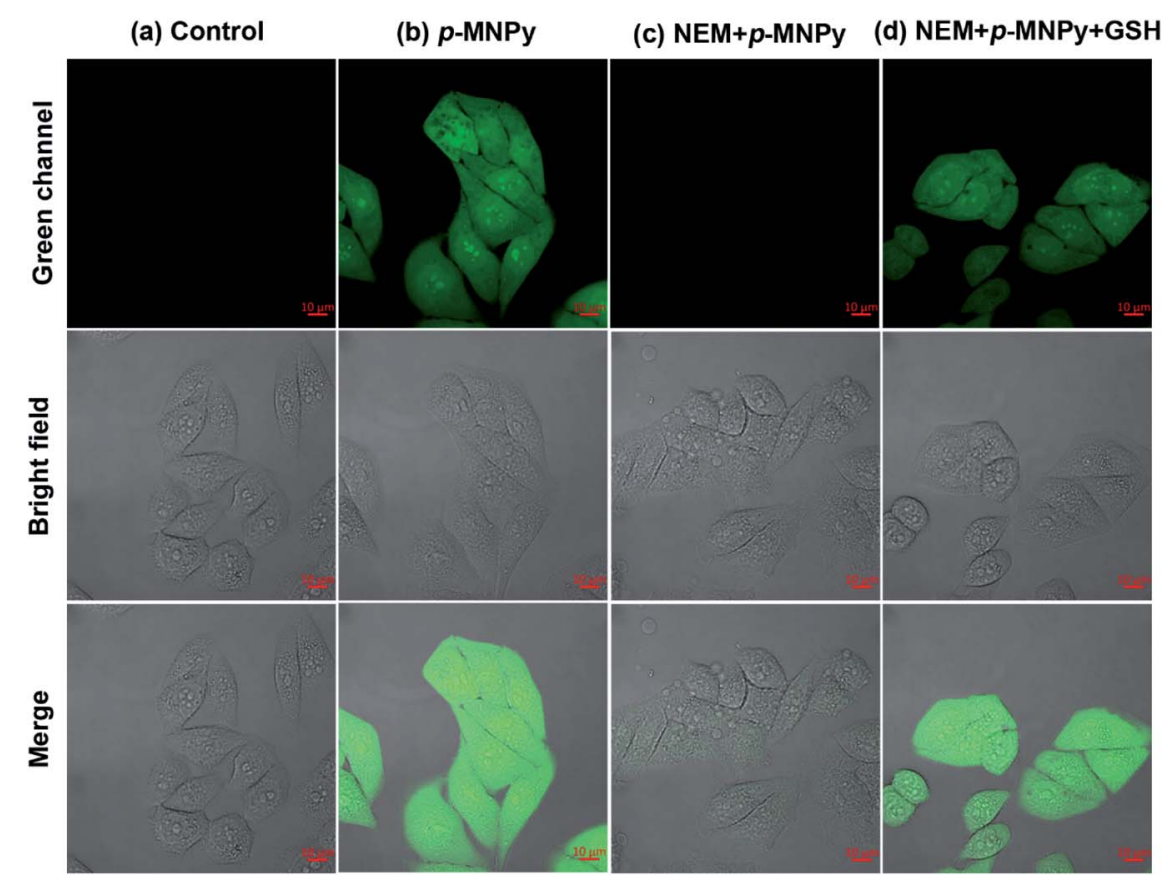

Fig. 6 The confocal images of live HeLa cells: (a) control group; (b) incubated with the probe $p$-MNPy for 30 min; (c) pretreated with NEM for $60 \mathrm{~min}$, and then incubated with the probe for $30 \mathrm{~min}$; (d) pretreated with NEM for $60 \mathrm{~min}$, with the probe for $30 \mathrm{~min}$, and then treated with GSH for 60 min. Concentration: $p$-MNPy, $10 \mu$; NEM, 1 mM; GSH 1 mM. Excitation at $405 \mathrm{~nm}$. Emission collected at $490-580 \mathrm{~nm}$. Scale bar: $10 \mu \mathrm{m}$. 
(a) Control
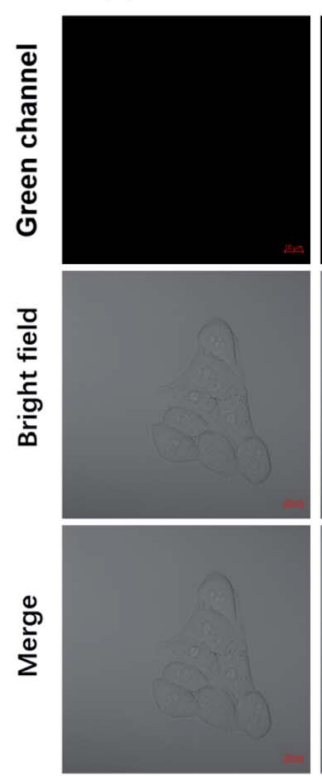

(e)

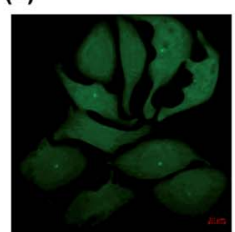

0 min

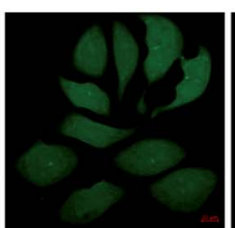

$10 \mathrm{~min}$ (b) $p$-MNPy
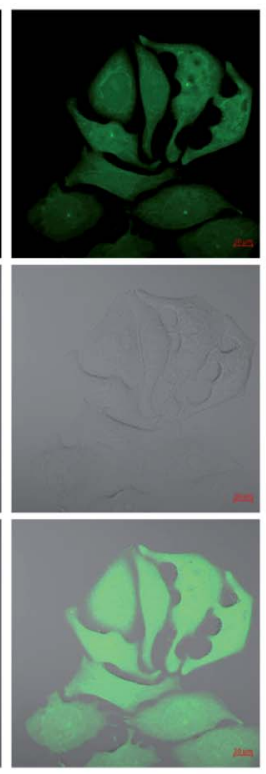

(c) $p-\mathrm{MNPy}+\mathrm{H}_{2} \mathrm{O}_{2}$
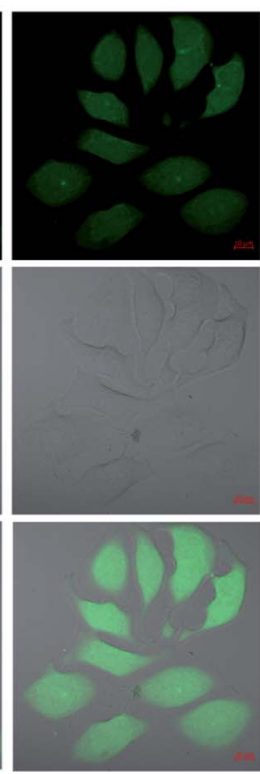

(d) $p-\mathrm{MNPy}+\mathrm{H}_{2} \mathrm{O}_{2}+\mathrm{GSH}$
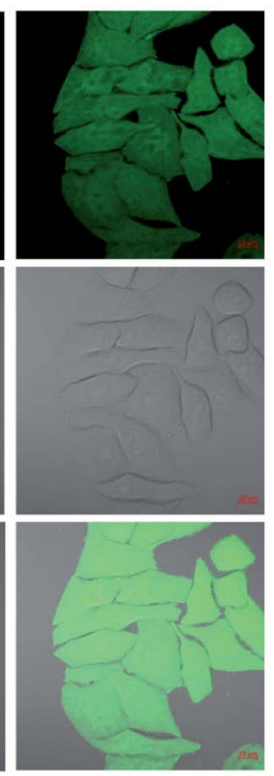

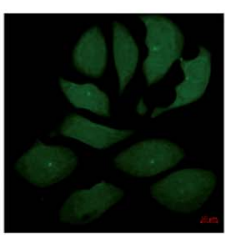

$20 \mathrm{~min}$

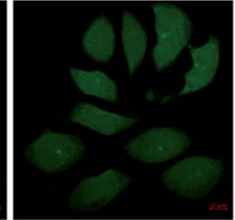

$30 \mathrm{~min}$

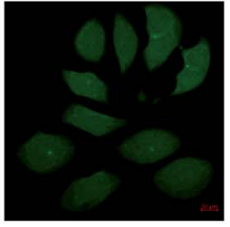

$40 \mathrm{~min}$

Fig. 7 The confocal images of live HeLa cells: (a) control group; (b) incubated with $p$-MNPy for 30 min; (c) incubated with $p$-MNPy for 30 min, and then treated with $\mathrm{H}_{2} \mathrm{O}_{2}$ for $40 \mathrm{~min}$; (d) treated with $p$-MNPy for $30 \mathrm{~min}$, with $\mathrm{H}_{2} \mathrm{O}_{2}$ for 40 min, and then with GSH for 60 min. (e) Real-time GSH imaging with $p$-MNPy in HeLa cells upon $\mathrm{H}_{2} \mathrm{O}_{2}$ treatment. Concentration: $p$-MNPy, $10 \mu \mathrm{M}_{;} \mathrm{H}_{2} \mathrm{O}_{2}, 1 \mathrm{mM} ; \mathrm{GSH} 1 \mathrm{mM}$. Excitation at $405 \mathrm{~nm}$. Emission collected at 490-580 nm. Scale bar: $10 \mu \mathrm{m}$.

As shown in Fig. S15, $\dagger$ HeLa cells were incubated with $\boldsymbol{p}$-MNPy in different concentrations for $24 \mathrm{~h}$. The cell viability was all above $90 \%$ when the probe concentration was in the range of $0-$ $20 \mu \mathrm{M}$. Considering $10 \mu \mathrm{M}$ of the probe was utilized in cell experiments, it was safe enough for the live cells. The confocal fluorescence images of the cells were shown in Fig. 6 . When the cells were incubated with $\boldsymbol{p}$-MNPy for $30 \mathrm{~min}$, strong green fluorescence could be observed. However, almost no fluorescence was found when the cells were pretreated with NEM $(\mathrm{N}$ ethyl maleimide) to scavenge the intracellular biothiols, and then incubated with $\boldsymbol{p}$-MNPy, which manifested that the green fluorescence induced by $\boldsymbol{p}$-MNPy was probably ascribed to the selective interactions with biothiols. And when this group was subsequently treated with GSH, the green fluorescence recovered markedly. It was now almost certain that the probe $\boldsymbol{p}$-MNPy could specifically respond to GSH. To study the reversibility of the probe, the cells were stimulated by $\mathrm{H}_{2} \mathrm{O}_{2}$ to change the levels of intracellular GSH. As shown in Fig. 7, upon $\mathrm{H}_{2} \mathrm{O}_{2}$ treatment, the fluorescence images of the cells pretreated by $\boldsymbol{p}$-MNPy became noticeably darker over time, while the brightness could restore again when the cells were treated with additional GSH. This revealed that the probe successfully sensed the fluctuations of the GSH. In a word, $\boldsymbol{p}$-MNPy could image the GSH selectively and reversibly in living cells.

\section{Conclusion}

In conclusion, three probes, $\boldsymbol{o}$-MNPy, $\boldsymbol{m}$-MNPy and $\boldsymbol{p}$-MNPy, were designed and synthesized with minor structural differences in the Michael acceptor through the regulation of the connection mode of the pyridine group. The response performances of these probes toward the biothiols were evaluated taking the true intracellular biothiol contents into account, and $\boldsymbol{p}$-MNPy showed a better comprehensive performance with higher fluorescence intensity enhancement and faster recognition speed than the other two, demonstrating the advantages of the $p$-connection mode of pyridine group that could afford the probe both higher reactivity and better fluorescence properties. Further studies showed $\boldsymbol{p}$-MNPy revealed good selectivity, satisfactory sensitivity, and excellent $\mathrm{pH}$ adaptability during the detection of Cys and GSH. What's more, it could respond to GSH reversibly. Finally, the probe $\boldsymbol{p}$-MNPy was utilized to image the endogenous GSH and track the GSH fluctuations under the oxidative stress in living cells.

\section{Conflicts of interest}

There are no conflicts of interest to declare. 


\section{Acknowledgements}

This work was financially supported by the National Natural Science Foundation of China (No. 51703171) and Natural Science Foundation of Hubei Province (No. 2019CFB404). The authors would like to thank Shiyanjia Lab for the support of cell imaging.

\section{References}

1 C. X. Yin, K. M. Xiong, F. J. Huo, J. C. Salamanca and R. M. Strongin, Fluorescent Probes with Multiple Binding Sites for the Discrimination of Cys, Hcy, and GSH, Angew. Chem., Int. Ed., 2017, 56, 13188-13198.

2 L. Y. Niu, Y. Z. Chen, H. R. Zheng, L. Z. Wu, C. H. Tung and Q. Z. Yang, Design strategies of fluorescent probes for selective detection among biothiols, Chem. Soc. Rev., 2015, 44, 6143-6160.

3 D. Chen and Y. Feng, Recent Progress of Glutathione (GSH) Specific Fluorescent Probes: Molecular Design, Photophysical Property, Recognition Mechanism and Bioimaging, Crit. Rev. Anal. Chem., 2020, 1-18, DOI: 10.1080/10408347.2020.1819193.

4 M. M. Mohamed and B. F. Sloane, Cysteine cathepsins: multifunctional enzymes in cancer, Nat. Rev. Cancer, 2006, 6, 764-775.

5 E. Weerapana, C. Wang, G. M. Simon, F. Richter, S. Khare, M. B. Dillon, D. A. Bachovchin, K. Mowen, D. Baker and B. F. Cravatt, Quantitative reactivity profiling predicts functional cysteines in proteomes, Nature, 2010, 468, 790795.

6 S. A. Lipton, Y. Choi, H. Takahashi, D. Zhang, W. Li, A. Godzik and L. A. Bankston, Cysteine regulation of protein function - as exemplified by NMDA-receptor modulation, Trends Neurosci., 2002, 25, 474-480.

7 S. M. Marino and V. N. Gladyshev, Cysteine function governs its conservation and degeneration and restricts its utilization on protein surfaces, J. Mol. Biol., 2010, 404, 902-916.

8 P.-Y. Chu and M.-Y. Liu, Amino acid cysteine induces senescence and decelerates cell growth in melanoma, $J$. Funct. Foods, 2015, 18, 455-462.

9 J. Lin, I. M. Lee, Y. Song, N. R. Cook, J. Selhub, J. E. Manson, J. E. Buring and S. M. Zhang, Plasma homocysteine and cysteine and risk of breast cancer in women, Cancer Res., 2010, 70, 2397-2405.

10 J. D. Finkelstein and J. J. Martin, Homocysteine, Int. J. Biochem. Cell Biol., 2000, 32, 385-389.

11 G. Wu, Y. Fang, S. Yang, J. R. Lupton and N. D. Turner, Glutathione Metabolism and Its Implications for Health, $J$. Nutr., 2004, 134, 489-492.

12 C. Hwang, A. J. Sinskey and H. F. Lodish, Oxidized Redox State of Glutathione in the Endoplasmic Reticulum, Science, 1992, 257, 1496-1502.

13 Y. X. Zou, M. S. Li, Y. L. Xing, T. T. Duan, X. J. Zhou and F. B. Yu, Bioimaging of Glutathione with a Two-Photon Fluorescent Probe and Its Potential Application for Surgery Guide in Laryngeal Cancer, ACS Sens., 2020, 5, 242-249.
14 D. M. Townsend, K. D. Tew and H. Tapiero, The importance of glutathione in human disease, Biomed. Pharmacother., 2003, 57, 145-155.

15 H. J. Park, C. W. Song, S. Sarkar, Y. W. Jun, Y. J. Reo, M. Dai and K. H. Ahn, A caveat to common hemicyanine dye components and their resolution, Chem. Commun., 2020, 56, 7025-7028.

16 K. Dou, W. Huang, Y. Xiang, S. Li and Z. Liu, Design of Activatable NIR-II Molecular Probe for In Vivo Elucidation of Disease-Related Viscosity Variations, Anal. Chem., 2020, 92, 4177-4181.

17 H. M. Kim and B. R. Cho, Small-molecule two-photon probes for bioimaging applications, Chem. Rev., 2015, 115, 50145055.

18 Y. Zhou, J. Hua, B. Z. Tang and Y. Tang, AIEgens in cell-based multiplex fluorescence imaging, Sci. China: Chem., 2019, 62, 1312-1332.

19 D. Wang and B. Z. Tang, Aggregation-Induced Emission Luminogens for Activity-Based Sensing, Acc. Chem. Res., 2019, 52, 2559-2570.

20 D. Chen, Z. Long, Y. Sun, Z. Luo and X. Lou, A red-emission probe for intracellular biothiols imaging with a large Stokes shift, J. Photochem. Photobiol., A, 2019, 368, 90-96.

21 D. Chen, J. Yang, J. Dai, X. Lou, C. Zhong, X. Yu and F. Xia, A low background D-A-D type fluorescent probe for imaging of biothiols in living cells, J. Mater. Chem. B, 2018, 6, 52485255.

22 L. Chen, Y. Feng, Y. Dang, C. Zhong and D. Chen, A deep-red emission fluorescent probe with long wavelength absorption for viscosity detection and live cell imaging, Anal. Bioanal. Chem., 2020, 412, 7819-7826.

23 M. Zhang, L. Wang, Y. Zhao, F. Wang, J. Wu and G. Liang, Using Bioluminescence Turn-On To Detect Cysteine in Vitro and in Vivo, Anal. Chem., 2018, 90, 4951-4954.

24 J. Y. Wang, Z. R. Liu, M. G. Ren, X. Q. Kong and W. Y. Lin, A fast-response two-photon fluorescent probe for the detection of Cys over GSH/Hcy with a large turn-on signal and its application in living tissues, J. Mater. Chem. B, 2017, 5, 134-138.

25 X. X. Chen, L. Y. Niu, N. Shao and Q. Z. Yang, BODIPY-Based Fluorescent Probe for Dual-Channel Detection of Nitric Oxide and Glutathione: Visualization of Cross-Talk in Living Cells, Anal. Chem., 2019, 91, 4301-4306.

26 S. Chen, Y. Luo, N. Wang, X. P. Chen, Y. D. Guo, H. J. Deng, J. Xu, S. W. Chen and J. Y. Wang, Cascade reaction-based trinal-site probe for sensing and imaging of cysteine and glutathione, Talanta, 2020, 208, 119934.

27 M. H. Ren, L. F. Wang, X. Lv, Y. Q. Su, H. Chen, K. Y. Zhang, Q. Wu, Y. R. Bai and W. Guo, A rhodol-hemicyanine based ratiometric fluorescent probe for real-time monitoring of glutathione dynamics in living cells, Analyst, 2019, 144, 7457-7462.

28 J. Li, Y. Kwon, K. S. Chung, C. S. Lim, D. Lee, Y. K. Yue, J. Yoon, G. Kim, S. J. Nam, Y. W. Chung, H. M. Kim, C. X. Yin, J. H. Ryu and J. Yoon, Naphthalene-based fluorescent probes for glutathione and their applications 
in living cells and patients with sepsis, Theranostics, 2018, 8, 1411-1420.

29 L. Yuan, L. Wang, B. K. Agrawalla, S. J. Park, H. Zhu, B. Sivaraman, J. J. Peng, Q. H. Xu and Y. T. Chang, Development of Targetable Two-Photon Fluorescent Probes to Image Hypochlorous Acid in Mitochondria and Lysosome in Live Cell and Inflamed Mouse Model, J. Am. Chem. Soc., 2015, 137, 5930-5938.

30 S. Lee, J. Li, X. Zhou, J. Yin and J. Yoon, Recent progress on the development of glutathione (GSH) selective fluorescent and colorimetric probes, Coord. Chem. Rev., 2018, 366, 2968.

31 R. Zhang, J. Yong, J. Yuan and Z. P. Xu, Recent advances in the development of responsive probes for selective detection of cysteine, Coord. Chem. Rev., 2020, 408, 213182.

32 A. P. A. Dos Santos, J. K. da Silva, J. M. Neri, A. C. O. Neves, D. F. de Lima and F. G. Menezes, Nucleophilicity of cysteine and related biothiols and the development of fluorogenic probes and other applications, Org. Biomol. Chem., 2020, 18, 9398-9427.

33 D. Chen, Z. Long, Y. Dang and L. Chen, A new fluorescent probe for specific detection of cysteine with facile preparation and living cell imaging, Dyes Pigm., 2019, 166, 266-271.

34 D. Chen, Z. Long, Y. Dang and L. Chen, A novel fluorescent probe with red emission and a large Stokes shift for selective imaging of endogenous cysteine in living cells, Analyst, 2018, 143, 5779-5784.

35 Z. X. Liu, X. Zhou, Y. Miao, Y. Hu, N. Kwon, X. Wu and J. Yoon, A Reversible Fluorescent Probe for Real-Time Quantitative Monitoring of Cellular Glutathione, Angew. Chem., Int. Ed., 2017, 56, 5812-5816.

36 K. Umezawa, M. Yoshida, M. Kamiya, T. Yamasoba and Y. Urano, Rational design of reversible fluorescent probes for live-cell imaging and quantification of fast glutathione dynamics, Nat. Chem., 2017, 9, 279-286.

37 X. Jiang, J. Chen, A. Bajic, C. Zhang, X. Song, S. L. Carroll, Z. L. Cai, M. Tang, M. Xue, N. Cheng, C. P. Schaaf, F. Li, K. R. MacKenzie, A. C. M. Ferreon, F. Xia, M. C. Wang, M. Maletic-Savatic and J. Wang, Quantitative real-time imaging of glutathione, Nat. Commun., 2017, 8, 16087.

38 J. Chen, X. Jiang, C. Zhang, K. R. MacKenzie, F. Stossi, T. Palzkill, M. C. Wang and J. Wang, Reversible ReactionBased Fluorescent Probe for Real-Time Imaging of Glutathione Dynamics in Mitochondria, ACS Sens., 2017, 2, 1257-1261.

39 X. L. Liu, L. Y. Niu, Y. Z. Chen, Y. X. Yang and Q. Z. Yang, A multi-emissive fluorescent probe for the discrimination of glutathione and cysteine, Biosens. Bioelectron., 2017, 90, 403-409.

40 X. Lin, Y. Hu, D. Yang and B. Chen, Cyanine-coumarin composite NIR dye based instantaneous-response probe for biothiols detection and oxidative stress assessment of mitochondria, Dyes Pigm., 2020, 174, 107956.

41 J. Chen, Y. Li, X. Feng, M. She, W. Yao, X. Leng, P. Liu, S. Zhang and J. Li, An ICT-based fluorescent probe guided by theoretical calculation for selectively mapping endogenous GSH in living cells, Spectrochim. Acta, Part A, 2021, 246, 119041.

42 M. Zhu, L. Wang, X. Wu, R. Na, Y. Wang, Q. X. Li and B. D. Hammock, A novel and simple imidazo[1,2-a]pyridin fluorescent probe for the sensitive and selective imaging of cysteine in living cells and zebrafish, Anal. Chim. Acta, 2019, 1058, 155-165.

43 X. Dai, Z. Y. Wang, Z. F. Du, J. Cui, J. Y. Miao and B. X. Zhao, A colorimetric, ratiometric and water-soluble fluorescent probe for simultaneously sensing glutathione and cysteine/ homocysteine, Anal. Chim. Acta, 2015, 900, 103-110.

44 X. Hou, Z. Li, Y. Li, Q. Zhou, C. Liu, D. Fan, J. Wang, R. Xu and $\mathrm{Z}$. $\mathrm{Xu}$, ICT-modulated NIR water-soluble fluorescent probe with large Stokes shift for selective detection of cysteine in living cells and zebrafish, Spectrochim. Acta, Part A, 2021, 246, 119030.

45 K. Xiong, F. Huo, J. Chao, Y. Zhang and C. Yin, Colorimetric and NIR Fluorescence Probe with Multiple Binding Sites for Distinguishing Detection of Cys/Hcy and GSH in Vivo, Anal. Chem., 2019, 91, 1472-1478.

46 L. Yang, Y. A. Su, Y. N. Geng, Y. Zhang, X. J. Ren, L. He and X. Z. Song, A Triple-Emission Fluorescent Probe for Discriminatory Detection of Cysteine/Homocysteine, Glutathione/Hydrogen Sulfide, and Thiophenol in Living Cells, ACS Sens., 2018, 3, 1863-1869.

47 Y. Yang, Y. Z. Wang, Y. Feng, C. Cao, X. R. Song, G. L. Zhang and W. S. Liu, Light-driven visualization of endogenous cysteine, homocysteine, and glutathione using a nearinfrared fluorescent probe, J. Mater. Chem. B, 2019, 7, 7723-7728.

48 X. Jiang, Y. Yu, J. Chen, M. Zhao, H. Chen, X. Song, A. J. Matzuk, S. L. Carroll, X. Tan, A. Sizovs, N. Cheng, M. C. Wang and J. Wang, Quantitative imaging of glutathione in live cells using a reversible reaction-based ratiometric fluorescent probe, ACS Chem. Biol., 2015, 10, 864-874.

49 J. Chen, X. Jiang, S. Carroll, J. Huang and J. Wang, Theoretical and Experimental Investigation of Thermodynamics and Kinetics of Thiol-Michael Addition Reactions: A Case Study of Reversible Fluorescent Probes for Glutathione Imaging in Single Cells, Org. Lett., 2015, 17, 5978-5981.

50 Z. Long, L. Chen, Y. Dang, D. Chen, X. Lou and F. Xia, An ultralow concentration of two-photon fluorescent probe for rapid and selective detection of lysosomal cysteine in living cells, Talanta, 2019, 204, 762-768.

51 S. M. Shin, M. S. Lee, J. H. Han and N. Jeong, Assessing the guest-accessible volume in MOFs using two-photon fluorescence microscopy, Chem. Commun., 2014, 50, 289291.

52 Y. Yue, F. Huo, P. Ning, Y. Zhang, J. Chao, X. Meng and C. Yin, Dual-Site Fluorescent Probe for Visualizing the Metabolism of Cys in Living Cells, J. Am. Chem. Soc., 2017, 139, 3181-3185.

53 C. Liang, X. Chen, Q. Tang, W. Ji, Y. Jiang, L. Mao and M. Wang, An activity-based two-photon fluorescent probe 
for real-time and reversible imaging of oxidative stress in the rat brain, Chem. Commun., 2020, 56, 6368-6371.

54 H. Yan, F. Huo, Y. Yue, J. Chao and C. Yin, Rapid Reaction, Slow Dissociation Aggregation, and Synergetic Multicolor Emission for Imaging the Restriction and Regulation of
Biosynthesis of Cys and GSH, J. Am. Chem. Soc., 2021, 143, 318-325.

55 T. Li, F. Huo, J. Chao and C. Yin, Independent bi-reversible reactions and regulable FRET efficiency achieving real-time visualization of Cys metabolizing into $\mathrm{SO}_{2}$, Chem. Commun., 2020, 56, 11453-11456. 